\title{
Crenças e Atitudes Corretivas de Profissionais de Psicologia sobre a Homossexualidade
}

\author{
Jean Ícaro Pujol Vezzosi ${ }^{1}$ \\ ${ }^{1}$ Pontifícia Universidade Católica, RS, Brasil. \\ Damião Soares de Almeida Segundo ${ }^{3}$ \\ ${ }^{3}$ Universidade Federal do Rio Grande do Sul, RS, Brasil.
}

\author{
Mozer de Miranda Ramos² \\ ${ }^{2}$ Universidade Federal de Sergipe, SE, Brasil. \\ Angelo Brandelli Costa ${ }^{1}$ \\ ${ }^{1}$ Pontifícia Universidade Católica, RS, Brasil.
}

Resumo: Muitos profissionais da Psicologia no Brasil ainda consideram a homossexualidade um transtorno mental ou um desvio daquilo que se consideraria, apesar da ausência de evidências empíricas e dos aspectos bioéticos implicados nestes julgamentos. De acordo com a literatura, esses profissionais frequentemente praticam intervenções que visam mudar ou reparar a homossexualidade. Este estudo buscou avaliar as atitudes corretivas (AC) dos profissionais da Psicologia em relação a pacientes lésbicas, gays e bissexuais (LGB), através de um questionário online. A análise mostrou que $29,48 \%$ dos(as) profissionais exibem AC quando solicitado pelo(a) paciente, e 12,43\% quando não. Além disso, elas estão mais frequentemente presentes em psicoterapeutas cognitivo/comportamentais e familiares/sistêmicos. As análises de regressão demonstraram que os preditores mais fortes de AC foram a crença de que a homossexualidade é uma patologia; a crença de que as crianças criadas por pais/mães homossexuais (gays ou lésbicas ou bissexuais) têm maiores chances de desenvolverem problemas no desenvolvimento; a crença de que homossexualidade/bissexualidade é produto de um sentimento de que se é inadequado(a) ou incompetente nas relações heterossexuais; a crença de que existe uma causa para a homossexualidade/bissexualidade dos(as) pacientes; o gênero do(a) psicoterapeuta; e o nível de crença atual em relação a alguma religião. A aplicação adequada de intervenções com a população LGB deveria se dar por meio de aceitação e apoio, avaliação abrangente, enfrentamento ativo, apoio social e a exploração e desenvolvimento da identidade enquanto parte da diversidade sexual.

Palavras-chave: Atitudes Corretivas, Homossexualidade, Psicologia Clínica. 


\section{Beliefs and Corrective Attitudes of Psychology Professionals on Homosexuality}

Abstract: Many professionals in Psychology in Brazil still consider homosexuality a mental disorder or a deviation, despite the absence of empirical evidence and the bioethical aspects involved in these judgments. According to the literature, these professionals often practice interventions that aim to change or repair homosexuality. This study aimed to evaluate the corrective attitudes (CA) of Psychology professionals in relation to lesbian, gay and bisexual (LGB) patients, through an online questionnaire. The analysis showed that $29.48 \%$ of the professionals showed CA when they were asked by patients, and $12.43 \%$ when they were not. In addition, they are more often present in cognitive/behavioral and family/systemic psychotherapists. Regression analyses have demonstrated that the strongest predictors of CA were the beliefs that: homosexuality is a pathology; children raised by homosexual parents (gay or lesbian or bisexual) are more likely to develop developmental problems; homosexuality/bisexuality is the product of a feeling that one is inadequate or incompetent in heterosexual relationships; there is a cause for the homosexuality/bisexuality of patients. The genre of the psychotherapist and her/his current belief level in relation to some religion were also strong predictors. Appropriate implementation of interventions with the LGB population should take place through acceptance and support, comprehensive evaluation, active coping, social support, and the exploration and development of identity as part of sexual diversity.

Keywords: Corrective Attitudes, Homosexuality, Clinical Psychology.

\section{Creencias y Actitudes Correctivas de los Profesionales de Psicología sobre la Homosexualidad}

Resumen:Muchospsicólogos en Brasil todavía consideran quela homosexualidades un trastorno mental o una desviación de lo que se consideraría, a pesar de la falta de evidencia empírica y los aspectos bioéticos implicados en estos juicios. Según la literatura, estos profesionales a menudo practican intervenciones destinadas a cambiar o reparar la homosexualidad. Este estudio tuvo como objetivo evaluar las actitudes correctivas (AC) de los profesionales de la Psicología hacia pacientes lesbianas, gays y bisexuales (LGB), a través de un cuestionario en línea. El análisis mostró que el 29,48\% de los profesionales exhibían AC cuando el paciente lo solicitaba y el $12,43 \%$ cuando no lo hacían. Además, con mayor frecuencia están presentes en psicoterapeutas cognitivos/conductuales y familiares/sistémicos. Los análisis de regresión han demostrado que los predictores más fuertes de AC eran la creencia de que la homosexualidad es una patología; la creencia de que los niños criados por padres homosexuales (gays, lesbianas o bisexuales) tienen más probabilidades de adquirir problemas de desarrollo; la creencia de que la homosexualidad/bisexualidad es el producto de un sentimiento de que uno es inadecuado o incompetente en las relaciones heterosexuales; la creencia de que hay una causa para la homosexualidad/bisexualidad de los pacientes; el género del psicoterapeuta. y el nivel actual de creencia en relación con alguna religión. La implementación adecuada de las intervenciones con la población LGB debe realizarse a través de la aceptación y el apoyo, la evaluación integral, el afrontamiento activo, el apoyo social y la exploración y el desarrollo de la identidad como parte de la diversidad sexual.

Palabras clave: Actitudes Correctivas, Homosexualidad, Psicología Clínica. 


\section{Introdução}

A ciência médica e a Psicologia, ao discorrer sobre a sexualidade, teve como ponto de partida a heterossexualidade monogâmica como suposto padrão de normalidade à medida que desenvolvia um modo de atuação clínica para aquilo que considerava perversões, desvios sexuais ou patologias (Herek, 2010). Durante grande parte do século XX esta foi a perspectiva da Psicologia e da Psiquiatria a respeito da homossexualidade, inclusive presente nas primeiras edições do manual diagnóstico de Transtornos psiquiátricos da American Psychological Association (APA) (Costa \& Nardi, 2015a).

Indivíduos insatisfeitos com a própria manifestação de suas orientações LGB (lésbicas, gays e bissexuais) - por pressão do contexto da época em que viviam - passaram a procurar (ou foram obrigados a buscar) orientação psicológica para alcançar uma meta de mudança. As terapias conversivas se destinaram a modificar a expressão espontânea das orientações sexuais (Haldeman, 2002).

No entanto, na década de 1970 as pesquisas científicas defendendo uma visão não patológica da homossexualidade foram trazidas à atenção das associações psicológicas e psiquiátricas, que reconheceu os aspectos sociais subjacentes e o efeito do prejuízo da discriminação contra pessoas LGB (Drescher, 2006). Hoje, por exemplo, um grupo de trabalho internacional e interdisciplinar que está repensando a classificação dos transtornos sexuais e da saúde sexual da CID-11 considerou a eliminação de todas as categorias do código F66 (transtornos psicológicos e comportamentais associados ao desenvolvimento sexual e à sua orientação) que inclui a orientação sexual egodistônica. O objetivo foi eliminar qualquer "brecha" que permita a interpretação de uma resposta também esperada e natural do desenvolvimento como patologia, pois a patologização gera estigma e discriminação social (Diehl, Vieira, \& Mari, 2014). Com a retirada do código F66 da CID (homossexualidade ego-distônica), foi reconhecido que orientação sexual não está ligada a uma patologia e que não há uma ligação direta entre ela e qualquer doença (Barreto, 2017). Tal medida permitiu a

eliminação do principal argumento atual para as terapias de conversão (Teixeira, 2014).

A Psicologia no Brasil ofereceu atenção para a temática dos direitos humanos, por meio da publicação de seu código de ética do profissional e da Reso- lução $\mathrm{n}^{\circ} 01 / 1999$, que estabelece que a homossexualidade não constitui doença, distúrbio ou perversão e que os psicólogos não exercerão qualquer ação que favoreça a patologização de comportamentos ou práticas homoeróticas, nem adotarão ação coercitiva tendente a orientar homossexuais para tratamentos não solicitados (Toledo \& Pinafi, 2012).

O conjunto de atitudes institucionais que visaram despatologizar a homossexualidade, no entanto, não foi capaz de interromper com a visão aviltante da diversidade sexual, historicamente construída (Leal, 2004). No estado do Rio Grande do Sul, um estudo desenvolvido por Marques (2010) evidenciou a forma como pacientes LGB descrevem a prática psicológica de seus/suas terapeutas em relação as questões de sexualidade. Como resultados, são descritas a frequência de discursos de profissionais da Psicologia que deslegitimam o desejo LGB, com posturas de desqualificação ou concepções que compreendem as orientações sexuais não heterossexuais como falhas do desenvolvimento. Além disso, um estudo desenvolvido por Gaspodini e Falcke (2018) investigou de que forma as questões de diversidade sexual e de gênero são vivenciadas por profissionais da prática clínica. As práticas patologizantes identificadas entre os(as) psicólogos(as) foram motivadas por crenças em uma natureza biológica, psicológica, religiosa ou ético-moral sobre a diversidade sexual. Também foram destacadas a reprodução de estereótipos, uso de linguagem inadequada, formação clínica via conhecimentos patologizantes (explícitos e implícitos), silenciamentos e nenhum ou pouco contato interpessoal com pessoas LGBT.

Recentemente, visando analisar as concepções e práticas dos(as) psicólogos(as) frente às normativas do Conselho Federal de Psicologia (CFP) sobre a diversidade sexual e de gênero, foi realizado um estudo por Mesquita (2018) com profissionais da Psicologia. Através da análise de discurso, os resultados apontaram a coexistência de práticas éticas e preconceito, além da persistência de discursos e práticas que (re)inventam formas de abjeção e atribuições psicológicas justificando o desenvolvimento das orientações não heterossexuais. Além disso, foram destacadas aproximações sutis de essencialização da homo/bissexualidade com patologias, naturalizando a heterossexualidade e inferiorizando as experiências LGB.

Neste sentido, apesar de uma série de inciativas visando a despatologização das orientações sexuais 
LGB, os psicólogos(as) podem, por vezes, expressar suas crenças de gênero e percepções a respeito das orientações sexuais através da cultura em que vivem, indireta ou explicitamente (Drescher, 2010). Se esta cultura se baseia em princípios heteronormativos, os profissionais da Psicologia também a reproduzem (Herek, 2004).

As intervenções que se propõem a corrigir as manifestações espontâneas das orientações sexuais não heterossexuais - erroneamente - são denominadas atitudes corretivas (AC) (Lingiardi, Nardelli, \& Tripodi, 2015). As AC, disfarçadas de intervenções terapêuticas supostamente próprias de uma determinada abordagem teórica, são interpretações ou prescrições de condutas sobre os(as) pacientes Sabe-se que, ainda que tais atitudes estejam associadas a características específicas de um(a) terapeuta elas são impulsionadas, sobretudo pelo preconceito (Haldeman, 2002), e estão em desacordo com o fato de que as orientações sexuais são manifestações da diversidade humana (American Psychological Association [APA], 2009).

Este trabalho é uma adaptação de um estudo italiano, que avaliou as atitudes corretivas por meio da administração online de questionários em psicólogos (Lingiardi et al., 2015). Com uma amostra de 3.135 terapeutas, a análise das frequências mostrou que as atitudes corretivas foram reportadas por $58 \%$ dos participantes. Além disso, as AC do estudo foram preditas por variáveis que representam características demográficas, socioculturais e profissionais, bem como por crenças sobre a homossexualidade.

Partindo das evidências de atitudes corretivas de terapeutas no contexto brasileiro, o objetivo da presente pesquisa foi quantificar a frequência de AC e de crenças a respeito das orientações LGB, além de investigar variáveis que em conjunto indicariam a presença de AC através de características específicas dos(as) psicoterapeutas.

\section{Método}

\section{Participantes}

Considerando as especificidades para a execução de pesquisas, foram contatados os 23 Conselhos de Psicologia do Brasil, através de ligações telefônicas e e-mail enviados para as comissões de psicoterapia, direitos humanos e comunicação. No corpo do e-mail destacou-se a justificativa, os objetivos, o desenho do estudo e a forma com a qual o conselho poderia contribuir. De todos os conselhos regionais de Psicologia

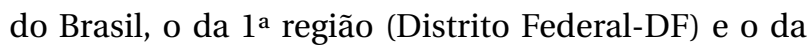
$4^{\text {a }}$ região (Minas Gerais-MG) concordaram participar da pesquisa enviando e-mail-convite aos psicólogos registrados, tal como nossa proposta. Os conselhos da $2^{\text {a }}$ Região (Pernambuco-PE), $3^{\text {a }}$ Região (Bahia-BA), $5^{\mathrm{a}}$ Região (Rio de Janeiro-RJ), 6a Região (São Paulo-SP),

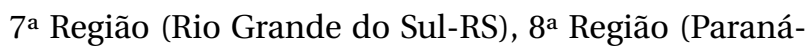
-PR), 9a Região (Goiás-GO), 16a Região (Espírito Santo-ES) e 18 Região (Mato Grosso-MT) concordaram em contribuir com a pesquisa com ressalvas. Estes, portanto, ofereceram a divulgação por meio de mídias sociais (Facebook e/ou Instagram) ou divulgação em seus websites. O restante dos conselhos não demonstrou interesse ou negou a participação na pesquisa. Um total de 891 profissionais acessaram o link, porém apenas 692 profissionais responderam ao questionário de forma completa.

Pessoas designadas mulheres e que se identificam assim correspondem a 71,82\% $(n=497)$ do grupo respondente. A faixa etária predominante foi a de 22 a 35 anos com $53,32 \%(n=369)$. No que diz respeito à orientação sexual, 75,29\% ( $n=521)$ dos psicólogos do estudo se designaram como heterossexuais e $24,71 \%$ ( $\mathrm{n}=171$ ) como não heterossexuais. A condição econômica autoidentificada em maior frequência foi “média”, com 77,31\% (n = 535). Quando indagados a respeito da filiação religiosa atual, o catolicismo foi a resposta predominante com 26,73\% ( $n=185$ ). Além disso, 40,75\% ( $\mathrm{n}=282)$ indicaram terem níveis de crença religiosa elevados.

Em relação a linha teórica mais utilizada para a atuação clínica, os(as) profissionais encontram-se predominantemente em Terapias Psicanalíticas e/ou Psicodinâmicas $(33,54 \%, \mathrm{n}=239)$ e Terapias Cognitivas e/ou Comportamentais $(25,29 \%, \mathrm{n}=175)$. A atividade profissional principal foi a Psicologia Clínica com $60,55 \%(n=419)$. Ainda que não seja a atividade principal, 23,99\% dos(as) participantes $(n=166)$ descrevem ser docentes em algum curso de formação/especialização/extensão/graduação/pós-graduação em Psicologia, à medida que apenas $15,75 \%(n=109)$ possuem curso de formação/especialização/extensão na área da diversidade sexual e de gênero. A amostra é composta em grande parte por psicólogos(as) pertencentes ao conselho da 4a Região (MG) $(63,58 \%, \mathrm{n}=440)$ e do Conselho da $1^{\text {a }}$ Região (DF) $(31,50 \%, \mathrm{n}=218)$. A Tabela 1 destaca as características dos(as) psicólogos(as). 
Tabela 1.

Caracterização dos participantes $(N=692)$.

\begin{tabular}{|c|c|c|c|}
\hline Variável & & $\mathrm{n}$ & $\%$ \\
\hline \multirow{2}{*}{ Designação ao nascimento } & Mulher & 497 & 71,82 \\
\hline & Homem & 195 & 28,17 \\
\hline \multirow{3}{*}{ Faixa etária } & 22 a 35 & 369 & 53,32 \\
\hline & 36 a 65 & 309 & 44,65 \\
\hline & 66 ou mais & 14 & 2,02 \\
\hline \multirow{4}{*}{$\begin{array}{l}\text { Orientação sexual } \\
\text { autoidentificada }\end{array}$} & Heterossexual & 521 & 75,29 \\
\hline & Homossexual & 94 & 13,58 \\
\hline & Bissexual & 71 & 10,26 \\
\hline & Outro & 6 & 0,87 \\
\hline \multirow{6}{*}{$\begin{array}{l}\text { Condição econômica } \\
\text { autoidentificada }\end{array}$} & Extremamente baixa & 1 & 0,14 \\
\hline & Baixa & 76 & 10,98 \\
\hline & Média & 535 & 77,31 \\
\hline & Alta & 77 & 11,12 \\
\hline & Extremamente alta & 2 & 0,29 \\
\hline & Omisso & 1 & 0,14 \\
\hline \multirow{6}{*}{$\begin{array}{l}\text { Linha teórica utilizada para } \\
\text { atuação na Clínica }\end{array}$} & Terapias Psicanalíticas e/ou Psicodinâmicas & 239 & 34,54 \\
\hline & Terapias Humanistas & 176 & 25,43 \\
\hline & Terapias Cognitivo e/ou Comportamentais & 175 & 25,29 \\
\hline & Terapias Familiares e/ ou Sistêmica & 60 & 8,67 \\
\hline & Outras & 38 & 5,49 \\
\hline & Omisso & 4 & 0,58 \\
\hline \multirow{6}{*}{ Atividade profissional principal } & Psicologia Clínica & 419 & 60,55 \\
\hline & Psicologia Social & 104 & 15,03 \\
\hline & Psicologia Organizacional e do Trabalho & 50 & 7,23 \\
\hline & Psicologia Escolar/Educacional & 39 & 5,63 \\
\hline & Docência em Psicologia & 35 & 5,06 \\
\hline & Outras & 45 & 6,50 \\
\hline \multirow{4}{*}{ Conselho de Psicologia } & $4^{a}$ Região - MG & 440 & 63,58 \\
\hline & $1^{\mathrm{a}}$ Região - DF & 218 & 31,50 \\
\hline & Outros & 29 & 4,20 \\
\hline & Omisso & 5 & 0,72 \\
\hline
\end{tabular}

\section{Procedimentos}

O questionário foi inserido em uma plataforma de coleta de dados (Qualtrics). Foi disponibilizado um link para o acesso à plataforma de dados, sem a necessidade de identificação do número de registro profissional, bem como do nome do(a) respondente. Foram enviados 2 e-mails convite para todos os profissionais registrados nos Conselhos Regionais de 
Psicologia (CRP), em duas semanas distintas. Os(as) participante concordaram com o Termo de Consentimento Livre e Esclarecido (TCLE). Em caso de dúvida, os(as) participantes foram instruídos a contatar o pesquisador responsável. Foram informados os benefícios da participação, bem como os riscos. Foram assinaladas garantias, tais como a de abandonar a pesquisa sem qualquer prejuízo. Foram atendidas as diretrizes e normas para pesquisas envolvendo seres humanos do Conselho Nacional de Saúde (CNS), de acordo com a Resolução n ${ }^{\circ} 466$, de 12 de dezembro de 2012. Este estudo foi aprovado pelo Comitê de Ética em Pesquisa da Pontifícia Universidade Católica do Rio Grande do Sul (PUCRS).

\section{Instrumentos}

Características sociodemográficas: os(as) profissionais responderam informações gerais, tais como idade, designação ao nascimento, identidade de gênero, estado civil, orientação sexual e condição socioeconômica.

Características socioculturais: os participantes da pesquisa foram solicitados a definir características relativas à intensidade de crença ou prática religiosa e outros tais como orientação política autoidentificada e a convivência na família e no trabalho com pessoas LGB.

Características profissionais: foram investigadas a atividade principal atual, a forma de atuação profissional, o exercício de docência, a linha teórica utilizada para atuação na clínica. Além disso, foram investigadas características profissionais relativas ao atendimento clínico, tais como o nível de preparação teórica e técnica para atender um(a) paciente LGB e se passou pela experiência de possuir pacientes que manifestaram a intenção de mudar a orientação sexual de homo/bissexual para heterossexual.

Crenças a respeito da homo/bissexualidade: esse grupo de questões avaliou pressupostos positivos e negativos a respeito das orientações não heterossexuais. Um grupo de questões considerou construções teóricas que entendiam a homo/bissexualidade como parte de um desenvolvimento fora da normalidade, derivadas do estudo original (Lingiardi et al., 2015); como no item: "a homossexualidade/bissexualidade é fruto de assédio ou abuso sexual sofrido na infância ou adolescência".

Foram acrescentadas crenças baseadas em pressupostos teóricos em relação a homo/bissexualidade que estão vinculadas a discursos de clínicos (Gaspodini \& Falcke, 2018; Marques, 2010): a homossexualidade/bissexualidade é fruto de assédio ou abuso sexual sofrido na infância ou adolescência; a homossexualidade/bissexualidade é consequência de uma identificação maior/excessiva com um dos genitores (Freud, 1905); a homossexualidade/bissexualidade é produto de um sentimento de que se é inadequado(a) ou incompetente nas relações heterossexuais (Ellis, 1965); a homossexualidade/bissexualidade é fruto de crenças irracionais e distorcidas desenvolvidas na infância e adolescência (Ellis, 1966); uma pessoa homossexual/ bissexual deve experimentar contato físico ou sexual com uma pessoa de outro gênero para ter certeza de sua homossexualidade/bissexualidade (Bergler, 1959; Ellis, 1965); o medo de uma relação com pessoas de outro sexo está relacionado ao desenvolvimento da homossexualidade/bissexualidade em homens e mulheres (Rado, 1949; Ferenczi, 1914); existe uma causa para a homossexualidade/bissexualidade dos(as) pacientes.

Um outro conjunto de questões avaliou pressupostos não patológicos, como no item "a homossexualidade é uma variante normal de sexualidade". Estas questões foram apresentadas com níveis de discordo totalmente, discordo em parte, nem concordo nem discordo, concordo em parte e concordo totalmente. Os níveis de concordância com as afirmações deste grupo também foram quantificados com uma escala do tipo Likert de 5 pontos.

Atitudes corretivas e conversivas: o questionário avaliou a atitude dos profissionais da Psicologia em relação a conversão/correção de pacientes LGB, por meio das afirmações: se o(a) paciente solicitar, o(a) psicólogo(a)/psicoterapeuta deve ajudar a mudar a orientação sexual de homossexual para heterossexual e o(a) psicólogo(a)/psicoterapeuta deve ajudar a mudar a orientação sexual de homossexual (gay ou lésbica ou bissexual) para heterossexual. Ambas afirmativas também foram avaliadas com uma escala do tipo Likert de 5 pontos.

\section{Análise de dados}

Os dados foram analisados a partir do SPSS 22. Todos os dados foram concebidos a partir da frequência e, visando tornar mais compreensível as atitudes corretivas e crenças a respeito da homossexualidade, considerou-se a conversão em dois polos para análise das variáveis: discordo totalmente e discordo 
parcialmente até concordo totalmente. Definiu-se, também, a frequência dos dados demográficos, socioculturais, profissionais e atitudes corretivas, além da prevalência das crenças e atitudes corretivas pelas abordagens teóricas. Buscou-se desvendar as variáveis que predizem o surgimento do desfecho (as atitudes corretivas quando o paciente solicitar), através da regressão hierárquica logística com etapas sucessivas, por meio do método foward condicional. Portanto, foi destacado o conjunto de dados que melhor prediz a concordância do(a) psicólogo(a) na utilização de atitudes corretivas, com e sem a solicitação do(a) paciente. As regressões se deram através do passo 1 (apenas para crenças e atitudes corretivas) e o passo 2 (as crenças e atitudes corretivas pelos dados sociodemográficos, socioculturais e profissionais), seguindo modelo do estudo original (Lingiardi et al., 2015).

\section{Resultados}

No que diz respeito às atitudes corretivas, $29,48 \%$ ( $\mathrm{n}=204)$ dos(as) profissionais da Psicologia concordam em algum nível que, se o(a) paciente solicitar, o(a) psicólogo(a)/psicoterapeuta deve ajudar a mudar a orientação sexual de homossexual para heterossexual. Além disso, 12,43\% ( $\mathrm{n}=86)$, dos profissionais de Psicologia concordam com a afirmação de que o psicólogo/psicoterapeuta deve ajudar a mudar a orientação sexual de homossexual (gay ou lésbica ou bissexual) para heterossexual.

Em relação a alguma mudança de opinião sobre a homossexualidade/bissexualidade ao longo da vida, a maior parte das psicólogas $(64,88 \%, \mathrm{n}=449)$ afirmaram que mantêm o posicionamento a respeito. Em termos de nível de preparação teórica e técnica para atender um(a) paciente LGB, os(as) terapeutas se situaram em grande parte como bastante preparados(as) $(36,42 \%, \mathrm{n}=252)$ e muito preparados(as) $(28,90 \%$, $\mathrm{n}=200$ ). No que diz respeito os(as) psicólogos(as) possuírem pacientes que manifestaram a intenção de mudar a orientação sexual de homossexual para heterossexual, $17,34 \%$ dos(as) psicólogos(as) $(n=120)$ passaram por esta experiência.

Dentre os cinco grandes grupos de abordagens teóricas, os(as) terapeutas cognitivo-comportamentais e familiares/sistêmicos são os(as) que apresentaram maiores níveis de AC, caso o(a) paciente solicite, em ordem de frequência $(34,86 \%, n=61 ; 33,33 \%$, $\mathrm{n}=20$ ) (Tabela 2). Por outro lado, em nosso estudo, os(as) terapeutas autoidentificados(as) como sistêmica/familiares $(18,33 \%, \mathrm{n}=11 ; 14,28 \%, \mathrm{n}=25) \mathrm{e}$ cognitivo-comportamentais são os que apresentaram as maiores frequências de $\mathrm{AC}$ sem o pedido do(a) paciente. Na verdade, os valores de AC estiveram muito próximos entre 4 grandes grupos de abordagens teóricas, exceto as terapias psicanalíticas e/ou psicodinâmicas, que apresentaram 23,85\% ( $n=57)$ para AC solicitada pelo(a) paciente e $9,62 \%(n=23)$ quando não solicitada. A Tabela 2 destaca a frequência de AC por abordagem teórica.

A Tabela 3 destaca a frequência das crenças a respeito da homo/bissexualidade. Quanto às crenças relativas a homossexualidade/bissexualidade, constatou-se que: $40,61 \%$ da amostra $(n=281)$ acreditam em algum nível que a falha de identificação com seu próprio papel de gênero pode levar a uma orientação LGB, assim como na pressuposição de que o medo de uma relação com pessoas de outro sexo estaria relacionado ao desenvolvimento destas orientações $(37,43 \%, \mathrm{n}=259)$.

A porcentagem de $96,97 \%$ dos(as) psicoterapeutas da amostra concordam totalmente com a pressuposição de que a homossexualidade é uma variante normal de sexualidade $(\mathrm{n}=671)$ e $51,59 \%$ $(\mathrm{n}=357)$ acreditam que existe uma causa para o desenvolvimento destas orientações sexuais. A parcela de $69,65 \%$ dos(as) psicólogos(as) pressupõe em algum nível que existe uma teoria explicativa válida sobre a origem psicológica da homossexualidade masculina e feminina.

Alguns grupos de abordagens apresentaram maiores níveis de frequência de crenças a respeito das orientações não heterossexuais. Os(as) terapeutas familiares/sistêmicos apresentaram os maiores escores na maior parte dos pressupostos, dentre eles o de que a homo/bissexualidade é resultado de dinâmicas familiares patológicas/disfuncionais $(53,33 \%, \mathrm{n}=32)$, de que são causadas por um trauma $(45,00 \%, \mathrm{n}=27)$ e de que seriam produtos de uma falha de identificação com o próprio papel de gênero $(48,33 \%, \mathrm{n}=29)$. Por outro lado, os(as) terapeutas cognitivo-comportamentais apresentaram maior prevalência na crença de que a homo/bissexualidade é uma patologia (11,43\%, $\mathrm{n}=20$ ) e de que uma pessoa homossexual/ bissexual deve experimentar contato físico ou sexual com uma pessoa de outro gênero para ter certeza de sua homossexualidade/bissexualidade $(30,29 \%, \mathrm{n}=53)$. Os(as) terapeutas de abordagens psicodinâmicas/ 
Tabela 2.

Frequências das atitudes corretivas por abordagem teórica.

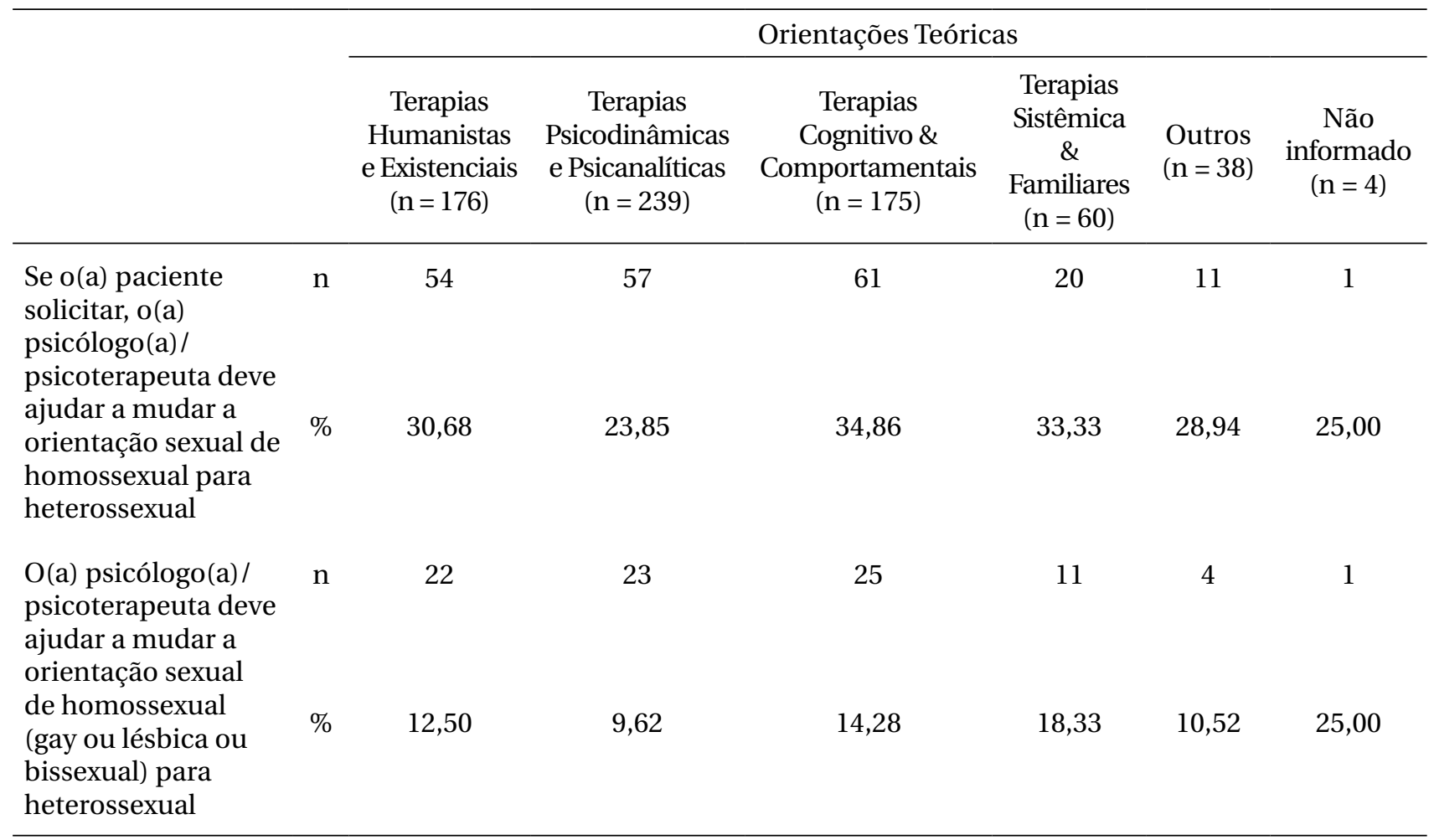

psicanalíticas, por sua vez, obtiveram altas frequências nas crenças de que a homossexualidade/bissexualidade é consequência de uma identificação maior/ excessiva com um dos genitores $(69,04 \%, \mathrm{n}=165)$ e de que existe uma causa para estas orientações sexuais $(54,39 \%, \mathrm{n}=130)$.

Quanto as variáveis consideradas na análise da regressão logística hierárquica, apenas as AC solicitadas serão descritas em nossa análise. A variável de AC solicitada pelo(a) paciente produziu o fator Nagelkerke $R 2$ de 0,32 e 0,33 no passo 1 e passo 2, respectivamente. Esses valores correspondem a variância de $32,00 \%$ e $33,00 \%$ para o conjunto de dados que melhor prediz a concordância na utilização de atitudes corretivas, quando o paciente solicita. No passo 1 , considerando todas as crenças descritas na Tabela 3, as análises demonstraram que os preditores mais fortes de AC com a solicitação do paciente, selecionados a partir do tamanho de efeito, foram (a) a crença de que a homossexualidade é uma patologia $(\mathrm{B}=1,188$; $\mathrm{p}<0,01$ ); (b) a crença de que as crianças criadas por pais/mães homossexuais (gays ou lésbicas ou bissexuais) têm maiores chances de desenvolverem problemas no desenvolvimento ( $B=0,939 ; p<0,001)$; (c) a crença de que homossexualidade/bissexualidade é produto de um sentimento de que se é inadequado(a) ou incompetente nas relações heterossexuais $(\mathrm{B}=0,829 ; \mathrm{p}<0,001)$; (d) a crença de que existe uma causa para a homossexualidade/bissexualidade dos(as) pacientes $(B=0,985 ; \mathrm{p}<0,001)$; Já no passo 2 , considerando, além das crenças, os dados demográficos da Tabela 1; (e) o gênero do(a) psicoterapeuta ( $\mathrm{B}=-0,577 ; \mathrm{p}<0,009$ ), e (f) o nível de crença atual em relação a alguma religião $(\mathrm{B}=0,239 ; \mathrm{p}<0,001)$, se mostraram preditores; vide Tabela 4.

A orientação sexual do(a) terapeuta e possuir um curso de formação/especialização/extensão na área da diversidade sexual e de gênero não foram estatisticamente significativos para o desfecho (não favorecem nem impedem uma atitude corretiva com a solicitação do(a) paciente).

\section{Discussão}

\section{Atitudes corretivas}

A parcela de $29,48 \%$ dos terapeutas $(n=204)$ concordam em algum nível que, se o(a) paciente 
Tabela 3.

Crenças a respeito da homo/bissexualidade $(n=692)$ e atitudes corretivas na amostra geral.

\begin{tabular}{|c|c|c|c|c|}
\hline & \multicolumn{2}{|c|}{ Discordo totalmente } & \multicolumn{2}{|c|}{$\begin{array}{c}\text { Discordo parcialmente até } \\
\text { concordo totalmente }\end{array}$} \\
\hline & $\mathrm{n}$ & $\%$ & $\mathrm{n}$ & $\%$ \\
\hline $\begin{array}{l}\text { A homossexualidade é uma variante normal de } \\
\text { sexualidade }\end{array}$ & 21 & 3,03 & 671 & 96,97 \\
\hline $\begin{array}{l}\text { Existe uma teoria explicativa válida sobre a origem } \\
\text { psicológica da homossexualidade masculina e feminina }\end{array}$ & 210 & 30,35 & 482 & 69,65 \\
\hline $\begin{array}{l}\text { A homossexualidade tem um forte componente } \\
\text { genético e biológico }\end{array}$ & 232 & 33,53 & 460 & 66,47 \\
\hline $\begin{array}{l}\text { A homossexualidade é resultado de dinâmicas } \\
\text { familiares patológicas/disfuncionais }\end{array}$ & 416 & 60,12 & 276 & 39,88 \\
\hline A homossexualidade é causada por um trauma & 465 & 67,20 & 227 & 32,80 \\
\hline $\begin{array}{l}\text { A homossexualidade é consequência de uma falha de } \\
\text { identificação com seu próprio papel de gênero }\end{array}$ & 411 & 59,39 & 281 & 40,61 \\
\hline A homossexualidade é um sintoma & 534 & 77,17 & 158 & 22,83 \\
\hline A homossexualidade é uma patologia & 637 & 92,05 & 55 & 7,95 \\
\hline $\begin{array}{l}\text { A homossexualidade é a expressão do desenvolvimento } \\
\text { psicológico incompleto }\end{array}$ & 557 & 80,49 & 135 & 19,51 \\
\hline $\begin{array}{l}\text { Os casais homossexuais são menos estáveis do que os } \\
\text { heterossexuais }\end{array}$ & 532 & 76,88 & 160 & 23,12 \\
\hline $\begin{array}{l}\text { Casais homossexuais devem ser autorizados a se casar } \\
\text { através do casamento civil }\end{array}$ & 70 & 10,12 & 622 & 89,88 \\
\hline $\begin{array}{l}\text { Homossexuais (gays ou lésbicas ou bissexuais) podem } \\
\text { ser bons pais/mães }\end{array}$ & 20 & 2,89 & 672 & 97,11 \\
\hline $\begin{array}{l}\text { As crianças criadas por pais/mães homossexuais } \\
\text { (gays ou lésbicas ou bissexuais) têm maiores chance de } \\
\text { desenvolverem problemas no desenvolvimento }\end{array}$ & 521 & 75,29 & 171 & 24,71 \\
\hline $\begin{array}{l}\text { A homossexualidade/bissexualidade é fruto } \\
\text { de assédio ou abuso sexual sofrido na infância } \\
\text { ou adolescência }\end{array}$ & 453 & 65,46 & 239 & 34,54 \\
\hline $\begin{array}{l}\text { A homossexualidade/bissexualidade é consequência de } \\
\text { uma identificação maior com um dos genitores }\end{array}$ & 315 & 45,52 & 377 & 54,48 \\
\hline $\begin{array}{l}\text { A homossexualidade/bissexualidade é produto } \\
\text { de um sentimento de que se é inadequado(a) ou } \\
\text { incompetente nas relações heterossexuais }\end{array}$ & 511 & 73,84 & 181 & 26,16 \\
\hline $\begin{array}{l}\text { A homossexualidade/bissexualidade é fruto de crenças } \\
\text { irracionais e distorcidas desenvolvidas na infância e } \\
\text { adolescência }\end{array}$ & 562 & 81,21 & 130 & 18,79 \\
\hline $\begin{array}{l}\text { Uma pessoa homossexual/bissexual deve experimentar } \\
\text { contato físico ou sexual com uma pessoa de outro } \\
\text { gênero para ter certeza de sua homossexualidade/ } \\
\text { bissexualidade }\end{array}$ & 521 & 75,29 & 171 & 24,71 \\
\hline $\begin{array}{l}\text { O medo de uma relação com pessoas de outro } \\
\text { sexo está relacionado ao desenvolvimento da } \\
\text { homossexualidade/bissexualidade em homens e } \\
\text { mulheres }\end{array}$ & 433 & 62,57 & 259 & 37,43 \\
\hline $\begin{array}{l}\text { Existe uma causa para a homossexualidade/ } \\
\text { bissexualidade dos(as) pacientes }\end{array}$ & 335 & 48,41 & 357 & 51,59 \\
\hline
\end{tabular}


Vezzosi, J. I. P., Ramos, M. M., Almeida Segundo, D. S., \& Costa, A. B. (2019). Atitudes Corretivas sobre Homossexualidade.

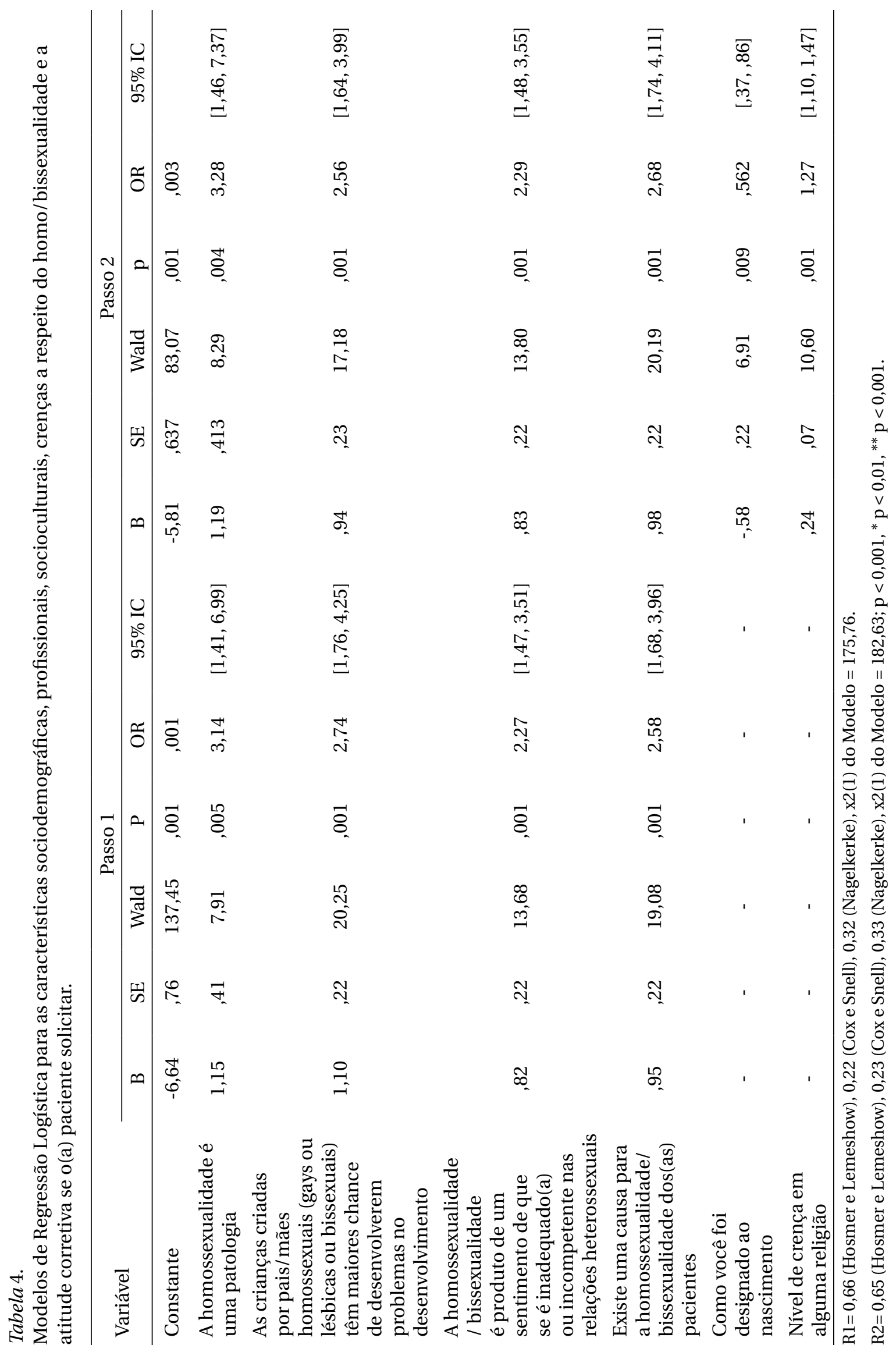


solicitar, o(a) psicólogo(a) deve ajudar a mudar a orientação sexual de homo/bissexual para heterossexual, evidenciando explicitamente as atitudes apesar da existência de uma resolução por parte do sistema conselho que torna essa atitude uma falta ética. Além disso, 12,43\% dos(as) psicólogos(as) brasileiros(as) ( $\mathrm{n}=86)$ de nosso estudo acreditam que devem ajudar a mudar a orientação sexual de homossexual (gay, lésbica ou bissexual) para heterossexual, sem o pedido do(a) paciente. Essa constatação é intrigante considerando que os espaços que mais deveriam desenvolver a função de amparo afetivo e emocional acabam por se mostrarem mais hostis a expressão espontânea da orientação sexual, deixando o(a) paciente ainda mais vulnerável emocionalmente (Silva, 2017).

Dentre os cinco grandes grupos de abordagens teóricas, os(as) terapeutas cognitivo-comportamentais e familiares/sistêmicos são os(as) que apresentaram maiores níveis de AC, caso o(a) paciente solicite, em ordem de frequência $(34,86 \%, \mathrm{n}=61$; $33,33 \%, \mathrm{n}=20$ ). Os(as) terapeutas autoidentificados(as) como sistêmica/familiares $(18,33 \%, \mathrm{n}=11$; $14,28 \%, \mathrm{n}=25$ ) e cognitivo-comportamentais são os que apresentaram as maiores frequências de AC sem o pedido do(a) paciente.

Em relação aos valores de AC em psicoterapeutas cognitivo-comportamentais isso pode ser explicado pela ausência de marco teórico em relação a orientações LGB, visto que não existem referências nos principais escritos dessa abordagem às orientações não heterossexuais (Gray, 2000). Considerando essa ser uma abordagem baseada em evidências, os(as) pacientes podem estar sujeitos(as) a falta de ancoragem do(a) terapeuta em relação a um modelo teórico afirmativo. Além disso, é possível que as formas de coping desadaptativas dos(as) pacientes possam ser compreendidas como patologias individuais ou essenciais a homo/bissexualidade, em vez de estratégias para sobreviver ao preconceito (Dunn, Gonzalez, Costa, Nardi, \& Iantaffi, 2014). A aplicação adequada de intervenções com a população LGB deveria se dar por meio de aceitação e apoio, avaliação abrangente, enfrentamento ativo, apoio social e a exploração e desenvolvimento de identidade enquanto parte da diversidade sexual (Trindade, 2004).

Em relação a frequência de AC nas terapias sistêmico e/ou familiares, essas já possuíram como característica principal um caráter desenvolvimentista, no qual foram delimitadas uma sequência previsível de transformações na organização familiar através do cumprimento de tarefas definidas (McGoldrick, 1995). Essa sequência, seguindo as tarefas que caracterizam as suas etapas (Robb, 2004) produziu uma noção de família nuclear que regulou não apenas a configuração familiar (família nuclear, pais heterossexuais casados e filhos), mas também as funções/papéis de cada indivíduo dentro dessa dinâmica (Moreira \& Nardi, 2007).

Portanto, a partir da elevada frequência de AC sem a solicitação do paciente dos(as) terapeutas sistêmicos/familiares, podemos pressupor que o formato normativo outrora produzido neste modelo de terapia continua a produzir atitudes interventivas visando corrigir sistemas familiares considerados desviantes (Bradt, 1995; Minuchin, 1982) para redirecionar a orientação sexual dos(as) familiares "afetados".

A Psicanálise possui produção teórica patologizante significativa em relação as orientações não heterossexuais (Haydée, 1999). Por um longo período, ela descreveu os relacionamentos homossexuais e a escolha de objetos como uma reprodução das posições masculinas e femininas, apegando-se, portanto, as normativas sociais que centralizam a heterossexualidade como parâmetro de normalidade (Klem, 2008). No entanto, esta abordagem teórica não obteve valores significativos quando comparados aos valores das outras abordagens em frequência no que diz respeito às AC. Atualmente, ela vem buscando apresentar uma teoria que diferencie claramente os aspectos descritivos e as construções daqueles aspectos normativos, ideológicos e preconceituosos com os que muitas vezes são confundidos. Neste sentido, a partir da relação da homossexualidade e direitos humanos, a psicanálise passou a assumir aos poucos o papel de não atribuir para si o poder de legislar ou de emitir juízos sobre o que está certo ou errado, sobre se a forma de estruturação da identidade ou do desejo sexual "escolhida" pelo sujeito é a adequada (Zambrano, 2006)

Para a psicanálise moderna, na verdade, pouco servem os conceitos de homossexualidade e heterossexualidade para o entendimento do sujeito (Klem, 2008). Estes conceitos impedem que se evidencie que as identidades são múltiplas e que estão constantemente sendo construídas. Esses conceitos acabam se apresentando, sob o ponto de vista da psicanálise, como noções entendidas como normativas que utili- 
zam a heterossexualidade como parâmetro e o que for diferente disso, desvio.

Em nossa hipótese, a frequência mais baixa de AC nas terapias psicodinâmicas/psicanalíticas é fruto da extensa crítica recebida em relação a sua postura histórica para com a diversidade sexual de gênero, o que acabou produzindo mudanças no posicionamento teórico e técnico entre terapeutas da psicanálise, em consonância com a orientação da International Psychoanalytical Association (IPA) (Roughton, 2003).

Ao mesmo tempo, de acordo com Zambrano (2006), a psicanálise considera seu papel exclusivamente da ordem do individual, não tendo legitimidade, nem clínica nem teórica, para emitir pareceres categóricos. Neste sentido, é possível também que a subjetividade do(a) paciente em uma sessão de psicoterapia/análise e a abstinência do(a) terapeuta possa também protegê-lo(a) de posturas corretivas e/ou conversivas (Maya, 2007), visto que psicólogos de orientação psicanalítica da amostra também apresentaram AC.

Para o grupo de profissionais da Psicologia que se identificaram como heterossexuais $(75,29 \%, \mathrm{n}=521)$, a porcentagem de $35,32 \%(n=184)$ concordam que, se o(a) paciente solicitar, o(a) psicólogo(a)/psicoterapeuta deve ajudar a mudar a orientação sexual de homossexual para heterossexual. Os psicólogos do estudo que se designarem como não heterossexuais $24,71 \%(n=171)$ surpreendentemente apresentaram $11,70 \%(n=20)$ de concordância em algum nível da afirmação. Esse dado corrobora o que foi encontrado no estudo italiano (Lingiardi et al., 2015). Embora tal nível de AC se apresente em menor frequência do que os terapeutas autoidentificados como heterossexuais, a orientação sexual não é uma variável preditora nesse estudo. De acordo com Lingiardi et al. (2015), a orientação sexual per se não é fator protetivo o suficiente para o uso de AC. Profissionais da Psicologia LGB também estão sujeitos aos preconceitos que podem reverberar com a homofobia internalizada dos clientes. Ao que parece, o sistema de ideias que estabelece a heterossexualidade como norma e que cria uma hierarquia na qual pessoas heterossexuais seriam superiores as que não são (Yep, 2002) é fortemente internalizado e externalizado também na conduta profissional desses terapeutas. Segundo Antunes (2017), a homofobia é composta de alguns elementos, tais como: machismo, heteronormatividade, heterossexismo e misoginia. No processo de socialização ela é introjetada por todas as pessoas, independente da sua orientação sexual. Cabe lembrar que as atitudes corretivas acabam por minimizar o papel da homofobia internalizada, dos atravessamentos sociais nos próprios terapeutas e das normas de gênero socialmente construídas, promovendo, portanto, práticas não terapêuticas de efeito prejudicial (Lingiardi et al., 2015).

\section{Frequências de crenças e variáveis demográficas, socioculturais e profissionais}

Em nosso estudo, cerca de 96,97\% dos(as) participantes concordam com a pressuposição de que a homossexualidade é uma variante normal de sexualidade $(\mathrm{n}=671)$. Em relação a alguma mudança de opinião sobre a homossexualidade/bissexualidade ao longo da vida, a maior parte das psicólogas $(64,88 \%$, $\mathrm{n}=449$ ) afirmaram que mantêm o posicionamento a respeito. Isso chama atenção, considerando que a homossexualidade/bissexualidade é vista por $40,61 \%$ da amostra $(n=281)$ como uma falha de identificação com seu próprio papel de gênero.

Considerando que $69,65 \%$ dos(as) psicólogos(as) pressupõem em algum nível que existe uma teoria explicativa válida sobre a origem psicológica da homossexualidade masculina e feminina, é provável que nesse raciocínio os desejos, comportamentos e as identidades sexuais sejam vistos como manifestações desviantes da sexualidade.

Ressalta-se isso justamente porque não há consenso a respeito das determinações da orientação sexual, havendo a investigação de aspectos genéticos, hormonais, dos padrões de atividade cerebral, de influências ambientais e da interrelação desses elementos (American Psychological Association [APA], 2008). Nesse sentido, uma leitura que busque uma etiologia das orientações sexuais LGB sem base empírica pode levar a consideração de que a fonte da insatisfação é a orientação per se, e não os elementos sociais promotores que estão associados através de evidências (Lingiardi et al., 2015).

Cabe ressaltar que, se há uma percepção patologizante em relação às orientações sexuais não heterossexuais por parte dos profissionais, ela pode se concretizar em intervenções ou interpretações de quaisquer abordagens teóricas de referência do(a) profissional da Psicologia. A busca de quaisquer justificativas que expliquem o suposto desvio sexual pode 
levar a pressuposição de que poderia ser modificado por intervenção clínica. Assim, isso leva a apresentação camuflada (ou explicita) através de técnicas ou interpretações da orientação teórica em si em uma sessão de psicoterapia.

Dentre as abordagens teóricas autoidentificadas, algumas delas apresentam maiores níveis de frequência de crenças a respeito das orientações não heterossexuais. Os(as) terapeutas familiares/sistêmicos apresentaram os escores mais elevados na maior parte dos pressupostos, dentre eles o de que a homo/ bissexualidade é resultado de dinâmicas familiares patológicas/disfuncionais $(53,33 \%, \mathrm{n}=32)$, de que são causadas por um trauma $(45,00 \%, \mathrm{n}=27)$ e de que seriam produtos de uma falha de identificação com o próprio papel de gênero $(48,33 \%, \mathrm{n}=29)$. Tais pressupostos estão em desacordo com avanços nas pesquisas da área, visto que não há evidências que apoiem a hipótese de que relações disfuncionais com os pais, abuso sexual ou qualquer outro evento adverso da vida na esfera familiar influenciem na orientação sexual (Perrin, 2002).

Por outro lado, os(as) terapeutas cognitivo-comportamentais apresentaram maior prevalência nas crenças de que a homo/bissexualidade é uma patologia $(11,43 \%, \mathrm{n}=20)$ e de que uma pessoa homossexual/ bissexual deve experimentar contato físico ou sexual com uma pessoa de outro gênero para ter certeza de sua homossexualidade/bissexualidade $(30,29 \%, \mathrm{n}=53)$.

Os(as) terapeutas de abordagens psicodinâmicas/psicanalíticas, por sua vez, obtiveram altas frequências nas crenças de que a homossexualidade/ bissexualidade é consequência de uma identificação maior/excessiva com um dos genitores $(69,04 \%$, $\mathrm{n}=165$ ) e de que existe uma causa para estas orientações sexuais $(54,39 \%, \mathrm{n}=130)$. Tais pressupostos são derivados especialmente do olhar Freudiano (Freud, 1905). Nesse sentido, a leitura de que a homo/bissexualidade é reflexo de uma identificação excessiva e a busca de justificativas para tanto estão associadas a leituras já produzidas pela psicanálise. Dentre as principais causas atribuídas as orientações LGB, destacam-se a visão de que seria a falta de resolução do complexo de Édipo (como produto de uma ansiedade de castração excessiva), uma fixação forte à figura da mãe e posterior identificação com ela, uma escolha de objeto narcisista e um complexo de édipo negativo (Lingiardi \& Capozzi, 2004). Portanto, Freud manteve-se atrelado aos pressupostos em voga à época. A pergunta a que se fez durante suas construções teóricas dos supostos motivos pelos quais uma pessoa executaria uma escolha objetal fora da norma evidencia isso.

Em termos de nível de preparação teórica e técnica para atender um(a) paciente LGB, os(as) terapeutas se situaram em grande parte como bastante preparados(as) $(36,42 \%, \mathrm{n}=252)$ e muito preparados(as) $(28,90 \%, \mathrm{n}=200)$. Considerando o nível de AC quando solicitada pelo(a) paciente, isso nos chamou atenção. O mesmo ocorreu no estudo de Lingiardi et al. (2015) em que muitos dos profissionais de Psicologia com menor preparo ou com menor atualização científica acreditam erroneamente que possuem treinamento suficiente para o exercício profissional com esta população - deixando, inclusive, de buscarem evidências para a prática clínica.

No que diz respeito às psicólogas possuírem pacientes que manifestaram a intenção de mudar a orientação sexual de homossexual para heterossexual, $17,34 \% \operatorname{dos}($ as) psicólogos(as) $(\mathrm{n}=120)$ passaram por esta experiência. Na compreensão atual, o interesse de pacientes por AC dos(as) terapeutas é impulsionado, dentre outros, pelo preconceito social (Haldeman, 2002).

Um relatório que revisou mais de 80 estudos denominado "esforços para mudança de orientação sexual" da APA (2009) trouxe entre suas conclusões que é improvável que indivíduos possam ter seu desejo pelo mesmo sexo diminuído ou o desejo pelo sexo oposto aumentado por meio de esforços para a mudança de orientação sexual. Além disso, as tentativas de mudança nos estudos demonstraram, de modo geral, que alguns indivíduos sofreram desfechos negativos quando submetidos a tais procedimentos, tais como perda do desejo sexual, depressão, suicídio e ansiedade.

É importante destacar que as experiências discriminatórias nos diferentes espaços podem ser formas de estresse agudo e crônico para a população LGB. Sabe-se que a discriminação possui efeito direto na saúde, alavancando transtornos mentais e agravando condições pré-existentes, como a ansiedade e depressão (Williams \& Mohammed, 2009). Tal posicionamento é endossado pelo CFP (2011) que destaca que além das implicações na saúde mental considerando os efeitos e agravos ao sofrimento psíquico, as terapias de reversão sexual não têm resolu- 
tividade. $\mathrm{O}$ atendimento de um pedido explícito de conversão por parte de um paciente, evidencia em um(a) terapeuta, portanto, o descumprimento explícito da Resolução $\mathrm{n}^{\circ}$ 01/1999. O posicionamento oficial do CFP destaca que a homossexualidade não é considerada patologia, e segue posição da Organização Mundial de Saúde (OMS). Ademais, AC ferem o princípio da dignidade humana de pessoas LGB - uma propriedade intrínseca - em um espaço que supostamente deveria transmitir cuidado ético e de confiança (Davison, 1991).

O relatório "esforços para mudança de orientação sexual” da APA (2009) propõe que o trabalho dos psicoterapeutas com tais pacientes se dê por meio da psicoterapia afirmativa - os maiores contrapontos de AC. Tal conjunto de posturas possui a compreensão de que a orientação sexual consiste em um dos vários aspectos pertencentes a constituição de um indivíduo, de sua personalidade e do sentido de si (Glassgold, 2008). Dessa forma, elas lidam com a homofobia internalizada do próprio terapeuta e do paciente, com o contexto social e político de se viver como uma pessoa da diversidade sexual e de gênero.

Ainda que não seja a atividade principal, 23,99\% dos(as) participantes $(\mathrm{n}=166)$ descrevem ser docentes em algum curso de formação/especialização/ extensão/graduação/pós-graduação em Psicologia, à medida que apenas $15,75 \%(n=109)$ possuem curso de formação/especialização/extensão na área da diversidade sexual e de gênero. Apesar de o estudo conduzido por Gaspodini e Falcke (2018) ter avaliado que práticas despatologizantes dos profissionais da Psicologia também são motivadas por formação clínica via conhecimentos específicos da diversidade sexual, essa variável não esteve relacionada a nenhum desfecho em nosso estudo. No entanto, os próprios autores perceberam que um dos temas relevantes entre os profissionais avaliados era o de que a questão LGB é comumente silenciada na clínica em razão do despreparo, incômodo, receio ou falta de apoio por parte de professores/as para discutir ou pesquisar sobre diversidade sexual e de gênero. Ao que parece, o desconhecimento do assunto ou invisibilidade durante a formação pode implicar em desfechos tais como o uso de AC por psicoterapeutas.

\section{Preditores de AC}

A crença de que a homossexualidade é uma patologia foi uma das preditoras de $A C(B=1,188 ; p<0,01)$.
Tal modo de concepção é derivado de muitas teorias da Psicologia que surgiram ao fim do século XIX, que consideraram a homossexualidade como patologia (Foucault, 1988; Souza, 2010). Durante grande parte do século XX essa foi a perspectiva da Psicologia e da psiquiatria a respeito da homossexualidade, inclusive presente nas duas primeiras edições do manual diagnóstico de Transtornos psiquiátricos da APA (Costa \& Nardi, 2015a). Ainda que ser alvo de qualquer tipo de violência possa levar a efeitos psicológicos negativos, agressões, que têm como base o preconceito, podem gerar consequências mais intensas e duradouras, justamente pelo fato de que estão direcionadas a um aspecto intrínseco da identidade enquanto pessoa. O preconceito e a discriminação contribuem para o aumento de desfechos negativos em saúde mental para esta população (Nunan \& Cerqueira-Santos, 2017). Entender a homo/bissexualidade como uma patologia é uma perspectiva aviltante e anacrônica, visto que a APA retirou a homossexualidade da segunda edição do DSM em 1973 (Carvalho, Silveira, \& Dittrich, 2011), assim como a OMS que, em 1992, removeu a homossexualidade da décima edição da classificação internacional de doenças (CID-10) (Nakajima, 2003).

A pressuposição de que as crianças criadas por pais/mães homossexuais (gays ou lésbicas ou bissexuais) têm maiores chance de desenvolverem problemas no desenvolvimento $(24,71 \%, \mathrm{n}=171)$ também foi preditora de AC. Essa crença é derivada de um modelo outrora produzido que considera necessária a presença de um "terceiro" para a separação psíquica entre mãe e filho, uma das atribuições da chamada "função paterna" (Zambrano, 2006). Tais crenças hierarquizantes em relação a homoparentalidade estão associadas a discriminação e ao preconceito (Farias, 2010) e a ideia de que somente uma "família tradicional" justificaria a união de pessoas do mesmo sexo (Costa \& Nardi, 2015b). As evidências inclusive, não apontam para diferenças significativas entre os filhos criados por tais famílias no que se refere a questões de desenvolvimento psicossocial, exceto no que diz respeito a forma como as crianças podem aprender a lidar com a homofobia, com sua consciência mais aguçada com relação à homossexualidade (Santos, Araújo, Negreiros, \& Cerqueira-Santos, 2018; Cerqueira-Santos \& Bourne, 2016; Tasker, 2005). Portanto, ao acreditarem em tal pressuposição, os(as) terapeutas podem estar revelando uma formação teórica inade- 
quada em relação a temática, visto que reproduzem leituras que não foram apoiadas por pesquisas empíricas e que atualmente são consideradas obsoletas (Lingiardi \& Capozzi, 2004).

No que diz respeito a atuação dos (as) psicólogos(as) com a população LGB no contexto brasileiro, a idade do(a) terapeuta não é uma variável preditora quando a AC é solicitada pelo(a) paciente, enquanto o gênero do(a) terapeuta é $(B=-0,577 ; p<0,01)$. Essa é uma diferença importante em relação aos resultados do estudo de AC na Itália, que apresentou o resultado inverso (Lingiardi et al., 2015). Porém, um estudo desenvolvido por Haslam e Levy (2006) que buscou identificar as implicações das crenças essencialistas sobre o preconceito contra a diversidade sexual apontou associações entre preconceito e gênero.

Considerando que terapeutas homens são afetados por modelos sociais de masculinidade hegemônica, é possível que isto se relacione com a heteronormatividade para a produção de atitudes corretivas (Yep, 2002). Tal conjuntura implica em AC camufladas de intervenções psicoterápicas que estão, dentre outras, marcadas pela ausência de reconhecimento das especificidades da população LGB (Herek, 2004). Apesar da existência da Resolução $\mathrm{n}^{\circ}$ 01/1999 do CFP para os(as) psicólogos(as) brasileiros(as), que afasta a homossexualidade do rol de patologias e, portanto, daquilo que pode ser alvo de cura, o caráter heteronormativo continua, entretanto, a se apresentar na construção e manutenção da clínica psicológica no Brasil (Marques, 2010).

O modelo educativo vivenciado pelo próprio profissional da Psicologia, sua visão política, e seu nível de contato com a diversidade sexual podem incorrer em AC (Lingiardi et al., 2015; Altemeyer \& Hunsberger, 1992). No entanto, essas não se apresentaram como variáveis preditoras, nesse estudo. No que diz respeito a ausência do poder preditivo da orientação política, isso contrapõe os resultados do estudo original que apontaram que a auto identificação para o espectro da direita (conservador) indicava o desfecho de AC (Lingiardi et al., 2015) e de outros estudos que apontaram relação entre crenças patologizantes sobre orientações LGB e conservadorismo político (Terrizzi, Shook, \& Ventis, 2010; Haslam \& Levy, 2006).

\section{Limitações}

Este estudo apresenta algumas limitações. A amostra foi por conveniência, considerando o interesse dos profissionais da Psicologia em participarem. Portanto, os dados não podem ser generalizados. Além disso, muitos CRP tiveram poucos profissionais que se disponibilizaram, em detrimento de dois deles com ampla participação (1 ${ }^{a}$ Região - DF e $4^{\text {a }}$ Região - MG). Apesar dos(as) psicoterapeutas apontarem afirmações a respeito de suas características profissionais, não é se é possível estimar que todas elas são correspondentes a prática clínica, ainda que a maior parte dos respondentes provavelmente possua maior interesse na prática clínica ao responder os questionários. O estudo também não investigou crenças sobre a natureza da homo/bissexualidade de matriz religiosa, étnico-morais e biológicas, que também poderiam predizer atitudes corretivas (Gaspodini \& Falcke, 2018; Lacerda, Pereira \& Camino, 2002). Por outro lado, considerando a formação dos profissionais da Psicologia e as diretrizes curriculares da graduação em Psicologia, a investigação das crenças mais frequentes e preditoras de AC pode fomentar mudanças na abordagem docente do tema e na necessidade de discussão das leituras teóricas utilizadas atualmente sobre as orientações LGB. Formações online para profissionais de saúde já se mostrar uteis para redução do preconceito contra diversidade sexual e de gênero no Brasil (Costa et al., 2016).

Para outros estudos sugere-se a investigação de atitudes corretivas de outros profissionais em relação a diversidade sexual, tais como os(as) profissionais da psiquiatria e de serviço social. Além disso, seria interessante a investigação de variáveis que possam aprofundar a utilização de AC dos psicoterapeutas com pacientes LGB, como por exemplo a expressão de gênero do(a) paciente e as intervenções conversivas mais frequentemente utilizadas.

\section{Conclusões}

Este é um estudo que investigou quantitativamente as atitudes corretivas de psicólogos(as), de diferentes abordagens teóricas, frente a pacientes LGB (Lésbicas, Gays e Bissexuais) que requerem ou não modificação de suas orientações sexuais. Como objetivos específicos analisamos as frequências de crenças a respeito de orientações não heterossexuais e das atitudes corretivas executadas pelos(as) psicoterapeutas com e sem a solicitação do(a) paciente. 
Com uma amostra de 692 terapeutas, a análise das frequências mostrou que as atitudes corretivas foram reportadas por 29,48\% dos participantes. Além disso, as AC foram preditas por variáveis que representam características demográficas, socioculturais e profissionais, bem como por pressupostos teóricos sobre a homossexualidade. A partir da quantificação da frequência e da investigação de variáveis em conjunto, foram indicadas a presença de AC através de características específicas dos(as) psicoterapeutas.

Em nosso estudo, podemos pressupor que características sociodemográficas, socioculturais e profissionais dos(as) psicoterapeutas influenciam em suas práticas profissionais em relação a diversidade sexual. No que diz respeito as crenças analisadas percebem-se que produzem um funcionamento em descompasso com avanços e com posicionamento da Psicologia em relação aos direitos humanos. Embora existam controvérsias e incertezas quanto à gênese da diversidade das orientações sexuais humanas, não há evidências que apoiem a hipótese de que relações disfuncionais com os pais, abuso sexual ou qualquer outro evento adverso da vida influenciem na orientação sexual (Perrin, 2002). Ao elencar que as AC estão associadas a características específicas de um terapeuta não deixamos de considerar que as mesmas estão implicadas, sobretudo, por um contexto social maior de preconceito, segundo perspectiva de Lingiardi et al. (2015).

$\mathrm{O}$ atendimento de pacientes LGB deve ocorrer por meio de um conjunto de princípios comprometidos com a prática terapêutica ética e validante, particularmente com aqueles que apresentam dificuldades relativas à sua homossexualidade (Moita, 2006). Portanto, a aplicação adequada de intervenções com a população LGB deve ocorrer por meio de aceitação e apoio, avaliação abrangente, enfrentamento ativo, apoio social e a exploração e desenvolvimento de identidade enquanto parte da diversidade sexual (Trindade, 2004). Tal conjuntura em um espaço de psicoterapia permite o fortalecimento de aliança terapêutica e o aumento de boas práticas e é intrinsecamente oposta ao formato executado por muitos psicólogos(as) brasileiros(as) que se propõem a converter e corrigir pacientes. Além disso, é importante ressaltar que a frequência de crenças em relação a orientações não heterossexuais dos(as) profissionais da Psicologia denota uma falha importante entre os tipos de aprendizado vivenciados pelo/o psicólogo/a na formação e as práticas clínicas resultantes desse aprendizado mediado ou não por suas crenças pessoais (Gaspodini \& Falcke, 2018).

\section{Referências}

Altemeyer, B., \& Hunsberger, B. (1992). Authoritarianism, religious fundamentalism, quest, and prejudice. The International Journal for the Psychology of Religion, 2(2), 113-133. https://doi.org/10.1207/s15327582ijpr0202_5

American Psychological Association - APA. (2008). Answers to your questions: For a better understanding of sexual orientation and homosexuality. Washington, DC: o autor.

American Psychologichal Association - APA. (2009). Report of the american psychological association task force on appropriate therapeutic responses to sexual orientation. Washington, DC: o autor. Recuperdado de http://www. apa.org/pi/lgbt/resources/therapeutic-response.pdf

Antunes, P. P. S. (2017). Homofobia internalizada: O preconceito do homossexual contra si mesmo. São Paulo, SP: Annablume.

Barreto, R. C. (2017). PDC 234/2011: A “cura gay” e a interferência do legislativo na liberdade científica no contexto da preservação das minorias dentro da sociedade democrática (Trabalho de conclusão de curso). Universidade de Brasília, Brasília, DF, Brasil.

Bergler, E. (1959). One thousand homosexuals: Conspiracy of silence, or curing and deglamorizing homosexuals? Paterson, NJ: Pageant.

Bradt, J. O. (1995). Tornando-se pais: Famílias com filhos pequenos. In B. Carter, \& M. McGoldrick (Orgs.), As mudanças no ciclo de vida familiar (1a ed., pp. 206-221). Porto Alegre, RS: Artes Médicas.

Carvalho, M. R. A., Silveira, J. M., \& Dittrich, A. (2011). Tratamento dado ao tema "homossexualidade" em artigos do journal of applied behavior analysis: Uma revisão crítica. Revista Brasileira de Análise do Comportamento, 7(2), 72-81. https://doi.org/10.18542/rebac.v7i2.1451 
Cerqueira-Santos, E., \& Bourne, J. (2016). Estereotipia de gênero nas brincadeiras de faz de conta de crianças adotadas por casais homoparentais. Psico-USF, 21(1), 125-133. https://doi.org/10.1590/1413-82712016210111

Conselho Federal de Psicologia - CFP. (2011). Psicologia e diversidade sexual: Desafios para uma sociedade de direitos. Brasília, DF: o autor.

Costa, A. B., \& Nardi, H. C. (2015a). Homofobia e preconceito contra diversidade sexual: Debate conceitual. Temas em Psicologia, 23(3), 715-726. https://doi.org/10.9788/TP2015.3-15

Costa, A. B., \& Nardi, H. C. (2015b). O casamento" homoafetivo" e a política da sexualidade: Implicações do afeto como justificativa das uniões de pessoas do mesmo sexo. Revista Estudos Feministas, 23(1), 137-150. https://doi.org/10.1590/0104-026X2015v23nlp/137

Costa, A. B., Pase, P. F., Guaranha, C., Caetano, A. H., Kveller, D., Catelan, R. F. et al. (2016). Effectiveness of a multidimensional web-based intervention program to change brazilian health practitioners' attitudes toward the lesbian, gay, bisexual and transgender population. Journal of Health Psychology, 21(3), 356-368. https://doi.org/10.1177/1359105316628748

Davison, G. C. (1991). Constructionism and morality in therapy for homosexuality. In J. Gonsiorek, \& J. Weinrich (Orgs.), Homosexuality: Research implications for public policy (pp. 137-148). Thousand Oaks, CA: Sage.

Diehl, A., Vieira, D. L., \& Mari, J. J. (2014). A CID-11 não reconhecerá possibilidades de patologização da homossexualidade. Revista Debates em Psiquiatria, 4, 20-15.

Drescher, J. (2006). An interview with Lawrence Hartmann, MD. Journal of Gay \& Lesbian Psychotherapy, 10(1), 123-137. https://doi.org/10.1300/J236v10n01_11

Drescher, J. (2010). Queer diagnoses: Parallels and contrasts in the history of homosexuality, gender variance, and the diagnostic and statistical manual. Archives of Sexual Behavior, 39(2), 427-460. https://doi.org/10.1007/ s10508-009-9531-5

Dunn, T. L., Gonzalez, C. A., Costa, A. B., Nardi, H. C., \& Iantaffi, A. (2014). Does the minority stress model generalize to a non-US sample? An examination of minority stress and resilience on depressive symptomatology among sexual minority men in two urban areas of Brazil. Psychology of Sexual Orientation and Gender Diversity, 1(2), 117-131. https://doi.org/10.1037/sgd0000032

Ellis, A. (1965). Sexo sem culpa e sem medo. São Paulo, SP: Papel.

Ellis, A. (1966). Arte e ciência do amor. São Paulo, SP: Bestseller.

Farias, M. O. (2010). Mitos atribuídos às pessoas homossexuais e o preconceito em relação à conjugalidade homossexual e a homoparentalidade. Revista de Psicologia da UNESP, 9(1), 104-115.

Ferenczi, S. (1914). The nosology of male homosexuality. In S. Ferenczi (Org.), First contributions to psychoanalysis. New York, NY: Brunner.

Foucault, M. (1988). História da sexualidade: Vol. 1 a vontade de saber. São Paulo, SP: Graal.

Freud, S. (1905). Três ensaios sobre a sexualidade infantil. In S. Freud, Obras completas de Sigmund Freud. Rio de Janeiro, RJ: Imago.

Gaspodini, I. B., \& Falcke, D. (2018). Sexual and gender diversity in clinical practice in psychology. Paidéia (Ribeirão Preto), 28, 1-9. https://doi.org/10.1590/1982-4327e2827

Glassgold, J. M. (2008). Bridging the divide: Integrating lesbian identity and orthodox judaism. Women \& Therapy, 31(1), 59-72. https://doi.org/10.1300/02703140802145227

Gray, J. (2000). Cognitive-behavioural therapy. In D. Davies, \& C. Neal (Eds.), Therapeutic perspectives on working with lesbian, gay and bisexual clients (pp. 24-38). Buckingham: Open University.

Haldeman, D. C. (2002). Gay rights, patient rights: The implications of sexual orientation conversion therapy. Professional Psychology: Research and Practice, 33(3), 260-264. https://doi.org/10.1037/0735-7028.33.3.260

Haslam, N., \& Levy, S. R. (2006). Essentialist beliefs about homosexuality: Structure and implications for prejudice. Personality and Social Psychology Bulletin, 32(4), 471-485. https://doi.org/10.1177/0146167205276516

Haydée, G. (1999). A psicanálise e os modernos movimentos de "afirmação homossexual". Psicologia: Ciência e Profissão, 19(2), 50-53. https://doi.org/10.1590/S1414-98931999000200007 
Herek, G. M. (2004). Beyond "homophobia": Thinking about sexual prejudice and stigma in the twenty-first century. Sexuality Research \& Social Policy, 1(2), 6-24. https:// doi.org/10.1525/srsp.2004.1.2.6

Herek, G. M. (2010). Sexual orientation differences as deficits: Science and stigma in the history of american psychology. Perspectives on Psychological Science, 5(6), 693-699. https:// doi.org/10.1177/1745691610388770

Klem, G. (2008). A homossexualidade e a clínica psicanalítica (Dissertação de mestrado). Pontifícia Universidade Católica de São Paulo, São Paulo, SP, Brasil.

Lacerda, M., Pereira, C., \& Camino, L. (2002). Um estudo sobre as formas de preconceito contra homossexuais na perspectiva das representações sociais. Psicologia: reflexão e crítica, 15(1), 165-178. https://doi.org/10.1590/ S0102-79722002000100018

Leal, I. (2004). Parentalidades: Questões de género e orientação sexual. In A. F. Cascais (Ed.), Indisciplinar a teoria: Estudos gays, lésbicos e queer (pp. 215-243). Lisboa: Fenda.

Lingiardi, V., \& Capozzi, P. (2004). Psychoanalytic attitudes towards homosexuality: An empirical research. The International Journal of Psychoanalysis, 85(1), 137-157. https://doi.org/10.1516/AAFK-H7N2-YVCA-27MC

Lingiardi, V., Nardelli, N., \& Tripodi, E. (2015). Reparative attitudes of italian psychologists toward lesbian and gay clients: Theoretical, clinical, and social implications. Professional Psychology: Research and Practice, 46(2), 132-139. https://doi.org/10.1037/pro0000016

Marques, D. M. (2010). A(s) clínica(s) psicológica(s) e a diversidade sexual: Percorrendo trajetórias de vida (Dissertação de mestrado). Universidade Federal do Rio Grande do Sul, Porto Alegre, RS, Brasil.

Maya, A. (2007). O que os analistas pensam sobre a homossexualidade? Psychê, 11(21), 85-104.

McGoldrick, M. (1995). As mudanças no ciclo de vida familiar. In B. Carter, \& M. Mcgoldrick, As mudanças no ciclo de vida familiar: Uma estrutura para a terapia familiar (pp. 7-29). Porto Alegre, RS: Artes Médicas.

Mesquita, D. T. (2018). Análise das concepções e práticas de psicólogas/os frente às normativas do conselho federal de psicologia sobre diversidade sexual e de gênero (Dissertação de mestrado). Universidade Federal de Juíz de Fora, Juiz de Fora, MG, Brasil.

Minuchin, S. (1982). Famílias: Funcionamento e tratamento. Porto Alegre, RS: Artes Médicas.

Moita, G. (2006). A patologização da diversidade sexual: Homofobia no discurso de clínicos. Revista Crítica de Ciências Sociais, (76), 53-72.

Moreira, L. E., \& Nardi, H. C. (2007). Maternidade, paternidade, homoparentalidade-reflexões sobre o exercício da parentalidade e as questões de gênero. In Anais de trabalhos completos do Encontro Nacional da Abrapso. Rio de Janeiro, RS, Brasil, 14.

Nakajima, G. A. (2003). The emergence of an international lesbian, gay, and bisexual psychiatric movement. Journal of Gay \& Lesbian Psychotherapy, 7(1/2), 165-188. https://doi.org/10.1300/J236v07n01_10

Perrin, E. C. (2002). Sexual orientation in child and adolescent health care. New York, NY: Kluwer.

Rado, S. (1949). Psychosexual development in health and disease. New York, NY: Grune \& Stratton.

Robb, M. (2004). Exploring fatherhood: masculinity and intersubjectivity in the research process. Journal of Social Work Practice, 18(3), 395-406. https://doi.org/10.1080/0265053042000314456

Roughton, R. (2003). The international psychoanalytical association and homossexuality. Journal of Gay \& Lesbian Mental Healthy, 7(1/2), 189-196. https://doi.org/10.1300/J236v07n01_11

Santos, J. V. D. O., Araújo, L. F. D., Negreiros, F., \& Cerqueira-Santos, E. (2018). Adoption of children by homosexual couples: The social representations. Trends in Psychology, 26(1), 139-152. https://doi.org/10.9788/tp2018.1-06pt

Silva, O. (2017). Trajetórias de vida e mudança de identidade sexual: Quando não se encontra o pote de ouro no final do arco-íris (Dissertação de mestrado). Universidade Federal do Espírito Santo, Vitória, ES, Brasil.

Souza, J. O. M. L. (2010). Terapias do "armário": Clínica, ética e homofobia (Trabalho de conclusão de curso). Centro Universitário de Brasília, Brasília, DF, Brasil.

Tasker, F. (2005). Lesbian mothers, gay fathers, and their children: A review. Journal of Developmental \& Behavioral Pediatrics, 26(3), 224-240. 
Psicologia: Ciência e Profissão 2019 v. 39 (n.spe 3), e228539,174-193.

Teixeira, N. B. V. (2014). “Cura gay é o meu caralho!”: A normalização da homossexualidade e a Resolução CFP 1/99 (Dissertação de mestrado). Universidade Federal do Goiás, Goiania, GO, Brasil.

Terrizzi, J. A., Jr., Shook, N. J., \& Ventis, W. L. (2010). Disgust: A predictor of social conservatism and prejudicial attitudes toward homosexuals. Personality and Individual Differences, 49(6), 587-592. https://doi.org/10.1016/j. paid.2010.05.024

Toledo, L. G., \& Pinafi, T. (2012). The psychological clinic and the LGBT public. Psicologia Clínica, 24(1), 137-163.

Trindade, J. R. (2004). De dores e de amores: Transformações da homossexualidade paulistana na virada do século XX (Tese de doutorado). Universidade de São Paulo, São Paulo, SP, Brasil.

Williams, D. R., \& Mohammed, S. A. (2009). Discrimination and racial disparities in health: Evidence and needed research. Journal of Behavioral Medicine, 32(1), 20-47. https://doi.org/10.1007/s10865-008-9185-0

Yep, G. A. (2002). From homophobia and heterosexism to heteronormativity: Toward the development of a model of queer interventions in the university classroom. Journal of Lesbian Studies, 6(3/4), 163-176. https://doi. org/10.1300/J155v06n03_14

Zambrano, E. (2006). Parentalidades" impensáveis": Pais/mães homossexuais, travestis e transexuais. Horizontes antropológicos, 12(26), 123-147. https://doi.org/10.1590/S0104-71832006000200006

Jean Ícaro Pujol Vezzosi

Mestre em Psicologia pela Pontifícia Universidade Católica (PUC-RS), Porto Alegre - RS. Brasil.

E-mail: jeanicaro@yahoo.com.br

(iD https://orcid.org/0000-0003-0127-7530

Mozer de Miranda Ramos

Doutorando em Psicologia pela Universidade Federal de Sergipe (UFS), São Cristóvão - SE. Brasil.

E-mail:mozeramos@gmail.com

(iD) https://orcid.org/0000-0001-5164-1543

Damião Soares de Almeida Segundo

Doutorando em Psicologia pela Universidade Federal do Rio Grande do Sul (UFRGS), Porto Alegre - RS. Brasil.

E-mail: damiao.soares@gmail.com

(iD) https://orcid.org/0000-0003-2407-0583

Angelo Brandelli Costa

Doutor em Psicologia e Professor do Programa de Pós-Graduação em Psicologia da Pontifícia Universidade Católica (PUC-RS), Porto Alegre - RS. Brasil.

E-mail: angelobrcosta@uol.com.br

(iD) https://orcid.org/0000-0002-0742-8152

Endereço para envio de correspondência:

Pontifícia Universidade Católica do Rio Grande do Sul, Avenida Ipiranga 6681, Prédio 11, Sala 933, 90619-900

Porto Alegre, Rio Grande do Sul, Brasil.

Recebido 10/09/2019

Aceito 04/10/2019

Received 09/10/2019

Approved 10/04/2019 
Recibido 10/09/2019

Aceptado 04/10/2019

Como citar:Vezzosi, J. I. P., Ramos, M. M., Almeida Segundo, D. S., \& Costa, A. B. (2019). Crenças e atitudes corretivas de profissionais de psicologia sobre a homossexualidade. Psicologia: Ciência e Profissão, 39(n.esp3), 174-193. https://doi.org/10.1590/1982-3703003228539

How to cite:Vezzosi, J. I. P., Ramos, M. M., Almeida Segundo, D. S., \& Costa, A. B. (2019). Beliefs and Corrective Attitudes of Psychology Professionals on Homosexuality. Psicologia: Ciência e Profissão, 39(n.esp3), 174-193. https://doi.org/10.1590/1982-3703003228539

Cómo citar:Vezzosi, J. I. P., Ramos, M. M., Almeida Segundo, D. S., \& Costa, A. B. (2019). Creencias y Actitudes Correctivas de los Profesionales de Psicología sobre la Homosexualidad. Psicologia: Ciência e Profissão, 39(n. esp3), 174-193. https:// doi.org/10.1590/1982-3703003228539 